\title{
Portfolio Management Practices of Investment Practitioners Active in the Long-Term Insurance Industry
}

\section{J H Mostert}

Business Initiation Unit, ABSA Corporate Bank, Cape Town

\section{S J Steel}

Department of Statistics and Actuarial Science, University of Stellenbosch

\section{F J Mostert}

Deptartment of Business Management, University of Stellenbosch

\section{ABSTRACT}

In the long-term insurance industry, sound financial investment decisions depend largely on the portfolio management practices of the investment practitioners concerned. The ability of the investment practitioners to make well-informed decisions, as well as the strategies and policies underlying portfolio management practices, are the main issues of this research. Important correlations amongst various aspects of the financial investment decisionmaking process, as well as their association with the general information pertaining to the long-term insurers (which were disclosed during the empirical study), emerge in the closing section of this paper. The conclusions should be of prime interest to long-term insurers as well as investment practitioners who are working in that industry.

JEL G 22

\section{INTRODUCTION}

This paper analyses the portfolio management practices of investment practitioners (including portfolio managers and investment analysts). These practices are of prime importance to the long-term insurance industry as they provide the basis for financial investment decisions. Information about the number of investment practitioners employed, the number of companies that they monitor, the extent to which they conduct independent research or make use of externally researched investment reports, provide substantial explanation of the ability of these investment practitioners to make well-informed financial investment decisions. Information about their portfolio management practices 
also indicate whether enterprises are assessed in isolation for financial investment purposes or whether risks are assessed from a portfolio point of view. This type of information is of great value, since it indicates whether an enterprise which in isolation may not appear to be an attractive investment opportunity (due to the risks attached to the enterprise), may still pass the criteria of investment practitioners because of its limited impact on the risk profile of the relevant portfolios. Another aspect which receives attention in this research relates to whether the same investment decision-making process is adhered to irrespective of whether long-term insurance assets or funds of other clients are invested. Finally, associations amongst various aspects of the financial investment decision-making process as well as their relation to the general information disclosed, are analysed.

\section{OBJECTIVE OF THE RESEARCH}

A study of the applicable portfolio management practices of investment practitioners active in the long-term insurance industry should help to explain how the related risks are assessed in practice. The objective of this research therefore embodies cognisance of the various aspects related to portfolio management practices, in order to enable institutional investors to assess and possibly improve their practices. To achieve this objective, a synopsis of the components of the financial investment decision-making process is essential, since portfolio management practices are a vital part of it. An empirical survey provides the information needed to assess the nature of the portfolio management practices concerned. The conclusions of this research should be useful to institutional investors, and persons employed in investment management.

\section{THE FINANCIAL INVESTMENT DECISION-MAKING PROCESS OF INVESTMENT PRACTITIONERS}

The financial investment decision-making process and the relationships between its various components, appear in Figure 1. 


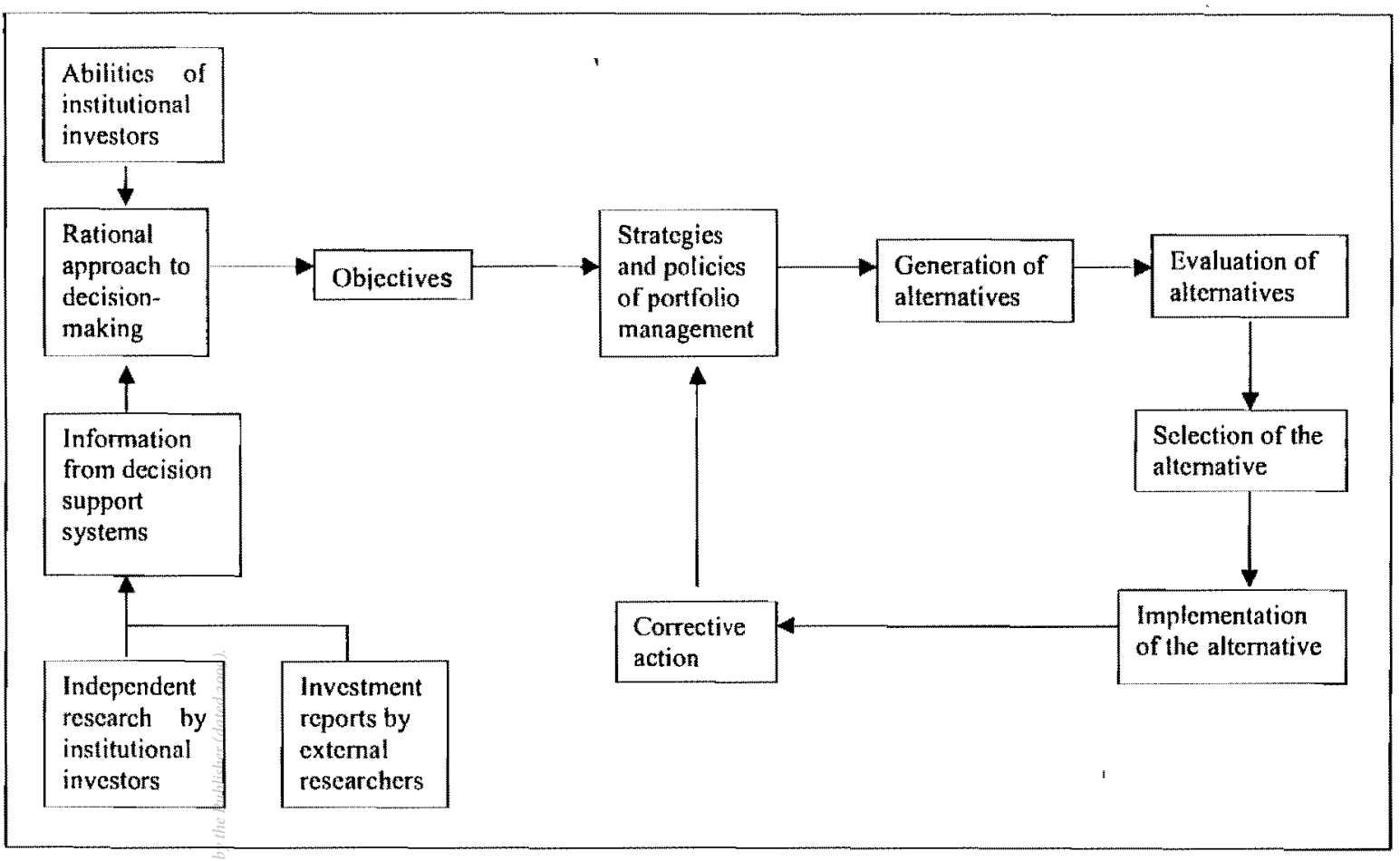


A rational (or scientific) approach to financial investment decision-making is the appropriate point of departure in this context (Rue \& Byars, 1989: 145). It is important to realise that some of the investment decisions will be programmed while others are unprogrammed decisions (Kroon, 1995: 185). Whether investment decisions are programmed or unprogrammed, depends on the extent to which a decision is structured, as well as the contingent factors involved in a particular financial investment decision.

The abilities of investment practitioners to make well-informed financial investment decisions, as well as an efficient decision support system are crucial prerequisites for a rational approach to financial investment decision-making (Shrivastava, 1994: 143). Table 1 relates to the empirical study and sets out the abilities of the investment practitioners, while Table 2 sets out the two sources of available information, namely, the investment practitioners' own research and the investment reports prepared by external researchers.

Rational approach actually starts with the formulation of the objectives that the investment practitioners pursue. The investment strategies and policies for portfolio management necessary to reach the objectives, are then formulated (Wheelen \& Hunger, 1995: 41). The detailed empirical aspects concerning the investment strategies and policies are shown in tables $3,4,5$ and 6 .

The generation of investment alternatives needs innovation and creativity, while technology and group techniques are often applied in this regard (Lussier, 1997: 112-16). The subsequent steps in financial investment decision-making involve the evaluation of the various investment alternatives and then the selection of the best alternative (Rue \& Byars, 1989: 145). The implementation of the chosen investment alternative is of vital importance (Thompson, 1997: 89). Timing is very important, as wrong timing can ruin the best of decisions (Plunkett \& Attner, 1997: 196). The final component of the decision-making process is the establishment of a control system (Plunkett \& Attner, 1992: 79-80). Comparing the actual results obtained with the objectives, may lead to corrective action of the investment strategies and policies of portfolio management.

Information obtained from the Financial Services Board indicated that 52 longterm insurers were registered on 3 November 1998 in South Africa (Van der Lith, facsimile, 1998). Five of the long-term insurers were excluded from the survey for the following reasons: 


\section{The insurers}

- did not have any equities in their investment portfolio;

- mainly invested in fixed property with only a negligible amount in unit trusts; or

- had insignificant exposure to equities.

Although 47 long-term insurers participated in the survey, not as many interviews were required, because there were cases where the same institution handled the financial investment management of more than one long-term insurer. In the event, 23 interviews were required (and actually took place) to cover the portfolio management practices of the 47 participating long-term insurers. A response rate of 100 per cent was therefore achieved.

It was evident that the majority of the officials interviewed had already achieved management status. The seniority of the people interviewed not only made a wealth of experience available to the survey, but meant that they could respond confidently about portfolio management practices at their organisations. The seniority of the people interviewed therefore contributed in more ways than one to the reliability of the information obtained.

\section{EMPIRICAL RESULTS}

The empirical results first illuminate the ability of the investment practitioners to make well-informed financial investment decisions (section 5.1). The strategies and policies of portfolio management are then discussed (section 5.2). The extent to which the portfolio management practices applicable to long-term insurance funds, are applicable to funds managed on behalf of other clients too, also receive attention (section 5.3). The closing section (5.4) of this research addresses the associations amongst aspects of portfolio management practices, as well as their association with the general information disclosed.

\subsection{Ability of Investment Practitioners to Make Well-Informed Financial Investment Decisions}

The ability of institutional investors to make well-informed financial investment decisions, is in the first place determined by the number of investment practitioners employed by them to perform this task, as well as by the number of companies they are required to monitor. Other things being equal, the ability of an institutional investor to make well-informed decisions weakens as the number of companies monitored by each investment practitioner increases. The responses by the participants in the survey are summarised in Table 1. 
Table 1 Summary of the number of investment practitioners which the participants in the survey employ and the number of enterprises which they monitor for the purpose of financial investment decision-making

\begin{tabular}{|c|c|c|}
\hline $\begin{array}{l}\text { Number of investment practitioners employed (a) } \\
\text { Number of companies monitored (b) } \\
\text { Number of companies monitored by each } \\
\text { investment practitioner }(\mathrm{c})=(\mathrm{b} / \mathrm{a})\end{array}$ & Respondents & $\begin{array}{l}\% \text { of } 23 \\
\text { interviews }\end{array}$ \\
\hline $1-5(a)$ & 8 & 34.8 \\
\hline $1-120(\mathrm{~b})$ & 6 & 26.1 \\
\hline $1-15(c)$ & -7 & 30.4 \\
\hline $6-10(a)$ & 7 & 30.4 \\
\hline $121-240(\mathrm{~b})$ & 10 & 43.5 \\
\hline $16-30(c)$ & 7 & 30.4 \\
\hline $11-15(\mathrm{a})$ & 5 & 21.7 \\
\hline $241-360(b)$ & 3 & 13.0 \\
\hline $31-45(c)$ & 5 & 21.7 \\
\hline $16 \cdot 20(a)$ & 1 & 4.3 \\
\hline $361-480(b)$ & 1 & 4.3 \\
\hline $46-60(c)$ & 3 & 13.0 \\
\hline $21-25$ (a) & 1 & 4.3 \\
\hline $481-600(\mathrm{~b})$ & 0 & 0.0 \\
\hline $61-75(c)$ & 0 & 0.0 \\
\hline $26-30$ (a) & 1 & 4.3 \\
\hline $601-720(b)$ & 3 & 13.0 \\
\hline $76-90(c)$ & 1 & 4.3 \\
\hline
\end{tabular}

Perusal of the information summarised in Table 1 indicates that the majority of the respondents ( 86.9 per cent) employed not more than 15 investment practitioners to monitor companies for the purpose of financial investment decision-making. To put this into perspective, it is interesting to note that the largest portion of the respondents ( 43.5 per cent) monitored between 121 and 240 companies, while the vast majority ( 82.6 per cent) indicated that they monitor a maximum of 360 companies. Consequently, in 60.8 per cent of the cases each investment practitioner is responsible for monitoring not more than 30 companies at any stage. This increases to 82.5 per cent if the cut-off is pegged at a maximum of 45 companies per investment practitioner. Just on this count alone, it is reasonable to conclude that the majority of investment practitioners responsible for investing the financial assets of long-term insurers, should be able to thoroughly assess each prospect included in their respective target group of companies. This implies that the largest 240 and possibly as many as 360 companies listed on the Johannesburg Stock Exchange, stand a 
reasonable chance of being subjected to rigorous analysis by the majority of investment practitioners who manage long-term insurance funds. On the other hand, it also implies that about 50 per cent of the 668 companies listed on the Johannesburg Stock Exchange at the time of the survey, received little or no attention from these investors, assuming that all investment practitioners analyse the main companies (JSE, 1998: 2). The possibility therefore exists that a significant number of listed companies are not correctly priced to take into account prevailing investment-related risks.

The involvement of external researchers reduces the possibility of investmentrelated risks being inadequately or incorrectly priced. It was therefore deemed necessary to determine the extent that respondents made ase of investment reports prepared by reputable external researchers. The survey results are summarised in Table 2.

Table 2 Summary of responses regarding the practice to do independent research as well as of the extent to which respondents make use of investment reports prepared by reputable external researchers

\begin{tabular}{|c|c|c|}
\hline $\begin{array}{l}\text { Respondents who do independent research (a) } \\
\text { Respondents who make use of investment reports } \\
\text { prepared by external researchers (b) }\end{array}$ & Number & $\begin{array}{l}\% \text { of } 23 \\
\text { interviews }\end{array}$ \\
\hline Not at all (a) & 2 & 8.7 \\
\hline (b) & 1 & 4.3 \\
\hline \multirow{2}{*}{ Once in a while ( $25 \%$ of the time) (a) } & 4 & 17.4 \\
\hline & 3 & 13.0 \\
\hline \multirow{2}{*}{ Sometimes ( $50 \%$ of the time) (a) } & 2 & 8.7 \\
\hline & 1 & 4.3 \\
\hline \multirow{2}{*}{$\begin{array}{l}\text { Fairly often (75\% of the time) (a) } \\
\text { (b) }\end{array}$} & 6 & 26.1 \\
\hline & 8 & 34.8 \\
\hline \multirow{2}{*}{$\begin{array}{r}\text { Always (a) } \\
\text { (b) }\end{array}$} & 9 & 39.1 \\
\hline & 10 & 43.5 \\
\hline
\end{tabular}

The information summarised in Table 2 indicates that it is standard practice for the majority of the respondents ( 65.2 per cent) to do independent research either fairly often or always. The investment practitioners are therefore not only able to subject the investment prospects to rigorous analysis as pointed out above, they also do so in fact. In addition, 78.3 per cent of the respondents indicated that they make use of investment reports prepared by reputable external researchers, either fairly often or always. The majority of financial investment decisions taken in respect of long-term insurance assets are therefore based on the research 
of more than one institution. This tends to improve the quality of financial investment decision-making and reduces incorrect assessment of risks.

Based on the findings reported in this section, it can be concluded that the vast majority of respondents should be able to make well-informed financial investment decisions. This is reflected by the manageable number of companies which the majority of investment practitioners are required to monitor, as well as the high incidence of independent research that is usually supported by investment reports prepared by reputable external researchers.

\subsection{Strategies and Policies for Portfolio Management Practices}

The portfolio management practices of the respondents disclose important information about the decision-making process as far as long-term insurance assets are concerned. Amongst others, they show whether enterprises are assessed in isolation or whether risks are assessed from a portfolio point of view. This type of information is of great value, since it indicates to what extent it is possible for an enterprise, which in isolation may not appear to be an attractive investment opportunity (due to the risks attached to it), to still pass the criteria of investment practitioners because of its limited impact on the risk profile of the relevant investment portfolios.

With the above-mentioned in mind, respondents were requested to comment on whether they followed the practice of specifying exposures for the purpose of portfolio management in respect of individual companies. Their responses are summarised in Table 3.

Table 3 Summary of responses regarding the practice of specifying exposures for the purpose of portfolio management in respect of individual companies

\begin{tabular}{|c|c|c|}
\hline Response & Number & $\begin{array}{c}\text { \% of 23 } \\
\text { interviews }\end{array}$ \\
\hline Yes & 21 & 91.3 \\
\hline No & 2 & 8.7 \\
\hline
\end{tabular}

It is evident that the vast majority of respondents (91.3 per cent) do specify exposures in portfolio management of individual companies. This implies that almost all enterprises are not only assessed in isolation, but also with regard to the impact which investment in them has on the investment portfolio. Enterprises which are disqualified in isolation for the purpose of financial investment decision-making, as a result of its investment-related risks, may 
therefore become attractive on account of a weak or even negative correlation of their investment-related risks with that of an existing investment portfolio. On the face of it, this result appears promising, because it can also be justified from a theoretical point of view. It does, however, not imply that the investment portfolios of most respondents are well balanced from the viewpoint of risk. An example would be a diversified portfolio that includes mainly banking, financial services, insurance, technology and media shares. From the industry point of view the portfolio might then appear to be satisfactorily balanced. From the viewpoint of a labour-related risk however, it might be highly unbalanced because it is biased towards knowledge-related workers whose risk profile differs from manual workers. In spite of this, it is promising to notice the awareness among respondents of the importance of portfolio considerations, for though particular risks might not receive the necessary attention directly, the possibility exists that it is taken into account indirectly when portfolios are constructed.

Respondents were also asked whether portfolio managers were allowed to deviate from the specified exposures of individual companies. The 21 respondents who did specify exposures reacted as follows:

Table 4 Summary of responses as to whether portfolio managers are allowed to deviate from exposures specified in respect of individual companies

\begin{tabular}{|l|c|c|}
\hline $\begin{array}{l}\text { Response to question whether portfolio } \\
\text { managers are allowed to deviate from the } \\
\text { exposures specified in respect of individual } \\
\text { companies }\end{array}$ & Number & $\begin{array}{c}\% \text { of } 21 \\
\text { responses }\end{array}$ \\
\hline Yes & 12 & 57.1 \\
\hline No & 9 & 42.9 \\
\hline
\end{tabular}

The summary of these responses indicates that although deviations from the specified exposures of individual companies were allowed in the majority of cases (57.1 per cent), a significant number of respondents ( 42.9 per cent) said that this was not allowed at their institutions. The former thus implies a larger degree of flexibility than the latter when financial investment decisions are taken. As a result of a flexible approach, certain companies might stand a bigger or smaller chance of being included in the investment portfolio than would have been the case if deviations were not allowed. In other words, if it is fashionable to invest in companies that employ mainly knowledge-related workers, manual worker-related companies stand a lesser chance to be included in the investment portfolio when a flexible approach is followed than if the opposite applies. The 
extent of this kind of risk is limited by the practice of respondents to specify boundaries beyond which deviations are not allowed. These boundaries, or maximum deviations, which are allowed from specified exposures, are summarised in Table 5.

Table 5 Summary of maximum deviations allowed from exposures specified in respect of individual companies

\begin{tabular}{|l|c|c|}
\hline $\begin{array}{l}\text { Maximum deviation which is allowed from Number } \\
\text { exposures which are specified in respect of } \\
\text { individual companies (expressed as a percentage } \\
\text { of the specified exposure) }\end{array}$ & $\begin{array}{l}\% \\
\text { responses }\end{array}$ \\
\hline $1 \%-5 \%$ & 4 & 44.4 \\
\hline $6 \%-10 \%$ & 4 & 44.4 \\
\hline $11 \%-15 \%$ & 0 & 0.0 \\
\hline $16 \%-20 \%$ & 1 & 11.1 \\
\hline
\end{tabular}

Note: Only nine of the 12 respondents who allow their portfolio managers to deviate from the exposures specified in respect of individual companies (refer to Table 4) disclosed the maximum deviation allowed.

A vast majority of respondents to this question ( 88.8 per cent) confirmed that they allowed a maximum deviation of 10 per cent in respect of specified exposures at individual companies. Only one respondent did not fall into this group, and mentioned that it allowed a maximum deviation of 20 per cent. It may therefore be concluded that the ability of portfolio managers to deviate from specified exposures in respect of individual companies is fairly limited.

Those respondents who did allow deviation from exposures were asked to specify the conditions which must be met for this to happen. The responses to this question may be summarised as follows:

Table 6 Summary of the conditions which must be met for portfolio managers to deviate from the exposures specified in respect of individual companies

\begin{tabular}{|l|c|c|}
\hline $\begin{array}{l}\text { Conditions which must be met for portfolio } \\
\text { managers to deviate from specified exposures }\end{array}$ & Number & $\begin{array}{l}\% \text { of } 6 \\
\text { responses }\end{array}$ \\
\hline Financial Services Board regulations & 2 & 33.3 \\
\hline Mandate of client & 2 & 33.3 \\
\hline Specified maximum deviation may not be exceeded & 1 & 16.7 \\
\hline Approved investment procedure must be adhered to & 1 & 16.7 \\
\hline
\end{tabular}


Note: Only six of the 12 respondents who allow deviations from the exposures specified in respect of individual companies (refer to Table 4) disclosed the conditions which must be met for these deviations to be allowed.

The above responses are not mutually exclusive, because although the respondents did not specifically mention it, they apply equally to each of them. In other words, although only two of the respondents mentioned Financial Services Board regulations as a condition which had to be met, the others also had to operate within these constraints, notwithstanding the fact that they did not mention it. This argument can be repeated for each of the four conditions that are listed in Table 6 . It may therefore be concluded that deviations from specified exposures in respect of individual companies when investment portfolios are constructed, are allowed on condition that portfolio managers adhere to the regulations/guidelines as specified by the Financial Services Board, their clients and employers.

\subsection{Extent to which the Financial Investment Decision-Making Process Applicable to Long-Term Insurance Funds is also Applicable to Funds Managed on behalf of Other Clients}

The respondents were asked to indicate to what extent the financial investment decision-making process applicable to long-term insurance assets deviates from that pertaining to assets managed on behalf of other clients. All 21 respondents who replied to this question indicated that the same process is followed irrespective of whose assets are managed. The two enterprises that did not respond to this question, stated that the question did not apply to them, because they are long-term insurers who do not manage any funds other than their own. The fact that a similar financial investment decision-making process is followed irrespective of whose funds are managed, adds considerable weight to the findings and conclusions of the empirical study. It is therefore reasonable to conclude that investment-related risks have a similar impact on financial investment decision-making by the respondents irrespective of whether longterm insurance funds or funds of other clients are managed.

\subsection{Correlations amongst Aspects Related to the Financial Investment Decision-Making Process and their Correlation with the General Information Disclosed}

Spearman's rank correlation coefficient $\left(r_{s}\right)$ is used as a measure of correlation (Mason \& Lind, 1990: 505-6). This coefficient can assume any value from $-1,00$ to $+1,00$ inclusive, with $-1,00$ indicating perfect negative correlation, $+1,00$ indicating perfect positive correlation, and 0,00 indicating no relationship at all between two sets of data. 
The significance of $r_{s}$ was also tested in each case. The test of significance was conducted to answer the question whether it was possible for the computed correlation to be due to chance, and that the correlation in the population was really 0,00 . The significance of $r_{s}$ was tested by the t-test hypothesis-testing procedure. The null hypothesis and the alternative hypothesis used in each case may be stated as follows:

Null hypothesis $\left(\mathrm{H}_{0}\right)$ : The correlation in the population is zero.

Alternative hypothesis $\left(\mathrm{H}_{1}\right)$ : The correlation in the population is different from zero.

Using the five per cent level of significance, the decision rule states that if the computed Student $t$ falls in the range between +2.08 and -2.08 , the null hypothesis cannot be rejected. The null hypothesis would however be rejected and the alternative hypothesis accepted, if the computed Student $t$ falls in the area of rejection, larger than +2.08 and smaller than -2.08 . If so, it is highly unlikely that there is no relationship between the two variables in the population.

Meaningful correlations which are significant at the five per cent level are summarised in Table 7.

Table 7 Summary of significant correlations amongst aspects related to the financial investment decision-making process, as well as their correlation with the general information disclosed

\begin{tabular}{|l|c|c|c|c|}
\hline \multicolumn{1}{|c|}{ Description } & $\begin{array}{c}\text { Num- } \\
\text { ber }\end{array}$ & $\begin{array}{c}\text { Spearman's } \\
\text { rank-order } \\
\text { coefficient }\end{array}$ & $\begin{array}{c}\text { Student } \\
\text { t(n-2) }\end{array}$ & $\begin{array}{c}\text { Proba- } \\
\text { bility- } \\
\text { level }\end{array}$ \\
\hline $\begin{array}{l}\text { Number of investment practitioners } \\
\text { employed \& Number of companies } \\
\text { monitored }\end{array}$ & 23 & 0.453 & 2.330 & 0.030 \\
\hline $\begin{array}{l}\text { Number of investment practitioners } \\
\text { employed \& Number of companies } \\
\text { monitored / Number of investment } \\
\text { practitioners employed }\end{array}$ & 23 & -0.487 & -2.554 & 0.018 \\
\hline $\begin{array}{l}\text { Number of investment practitioners } \\
\text { employed \& Number of respondents who do } \\
\text { independent research }\end{array}$ & 23 & 0.466 & 2.417 & 0.025 \\
\hline $\begin{array}{l}\text { Total investments / Number of investment } \\
\text { practitioners employed \& Use of investment } \\
\text { reports prepared by extemal researchers }\end{array}$ & 23 & 0.522 & 2.803 & 0.011 \\
\hline $\begin{array}{l}\text { Total assets / Number of investment } \\
\text { practitioners employed \& Use of investment } \\
\text { reports prepared by extemal researchers }\end{array}$ & 23 & 0.543 & 2.963 & 0.007 \\
\hline
\end{tabular}


Table 7 highlights the positive correlation between the number of investment practitioners employed who primarily focus on equity investments, and the approximate number of companies that are monitored for the purpose of financial investment decision-making (correlation coefficient of 0.453 and pvalue of 0.030 ). This can be expected, because the ability to monitor a larger number of companies will improve as more investment practitioners are employed. The question arises, whether the rate of increase between these two variables is the same? This may be answered by investigating the correlation between the number of investment practitioners employed and the number of companies monitored by each investment practitioner. As can be seen in Table 7 , these two variables are negatively correlated (correlation coefficient of -0.487 and p-value of 0.018 ) which shows that the number of companies which each investment practitioner has to monitor decreases, as the number of investment practitioners increases. Joint interpretation of these two correlations indicates that institutions which expand their investment management teams, are also able to increase the number of companies they monitor. Perhaps even more important, it reduces the number of companies which each investment practitioner has to monitor. Institutions with a relatively large number of investment practitioners, should therefore be able to spend more time on the analysis of each company they monitor than institutions which employ fewer investment practitioners. Other things being equal, institutions with a large number of investment practitioners should be able better to assess risks at the companies which they monitor. Companies who are of the opinion that their shares are undervalued on the Johannesburg Stock Exchange due to perceived risks, should therefore first approach institutions who employ large numbers of investment practitioners, because these institutions should have more time available to assess detailed information. This is reflected by the positive correlation coefficient of 0.466 ( $p$-value of 0.025 ) between the number of investment practitioners employed and the practice at those institutions to do independent research.

The last two correlations reported in Table 7, refer to the practice at institutions to make use of investment reports prepared by reputable external researchers. A positive correlation exists between total investments in respect of each investment practitioner and the practice of making use of investment reports prepared by reputable external researchers (correlation coefficient of 0.522 and p-value of 0.011 ). This is also the case when total assets in respect of each investment practitioner, is linked to the practice of making use of investment reports (correlation coefficient of 0.543 and p-value of 0.007 ). The two positive correlations are more or less of the same magnitude, because investments represent the bulk of the total assets of long-term insurers. The positive correlations obtained can be explained by a growing need among investment practitioners to validate their own investment recommendations with those of 
reputable external researchers as they are faced with the responsibility of managing larger investment funds.

\section{CONCLUSIONS}

The present study leads to a number of conclusions that are of prime importance for portfolio management practice in the long-term insurance industry:

- The majority of investment practitioners who are responsible for the financial investment decisions of long-term insurers, should be able to thoroughly assess each of the prospects included in their target groups of companies.

- The majority of investment practitioners either fairly often or always do independent research, and also make use of investment reports prepared by reputable extemal researchers.

- The vast majority of investment practitioners follow the practice of specifying exposures in respect of individual companies for the purpose of portfolio management.

- Approximately 57 per cent of the respondents are allowed to deviate from the exposures specified in respect of individual companies. The vast majority of them are allowed a maximum deviation of 10 per cent. Conditions which must be met for deviation include that investment practitioners must adhere to the regulations/guidelines specified by the Financial Services Board, their clients and employers.

- All respondents indicated that the same financial investment decisionmaking process is followed, irrespective of whether long-term insurance assets or assets managed on behalf of other clients are applicable.

- A positive correlation was found between the number of investment practitioners employed who primarily focus on equity investments, and the approximate number of companies monitored for the purpose of financial investment decision-making.

- The number of investment practitioners employed was negatively correlated with the number of companies which each investment practitioner has to monitor.

- A positive correlation was found between the number of investment practitioners employed and the practice at institutions to do independent research.

- It was found that a positive correlation exists between total investments (and also total assets) in respect of each investment practitioner and the practice to make use of investment reports prepared by reputable external researchers. 


\section{REFERENCES}

1 JOHANNESBURG STOCK EXCHANGE (JSE) (1998) Monthly Bulletin, JSE, Johannesburg.

2 KROON, J. (ed.) (1995) General Management (2 ${ }^{\text {nd }}$ ed.) Kagiso Tertiary, Pretoria.

3 LUSSIER, R.N. (1997) Management: Concepts, Applications, Skill Development, South-Western College Publishing, Cincinnati, Ohio.

4 MASON, R.D. \& LIND, D.A. (1990) Statistical Techniques in Business and Economics $\left(7^{\text {th }}\right.$ ed.) Richard D. Irwin, Homewood, Illinois.

5 PLUNKETT, W.R. \& ATTNER, R.F. (1992) Introduction to Management ( $4^{\text {th }}$ ed.) PWS-Kent Publishing Company, Boston, Massachusetts.

6 PLUNKETT, W.R. \& ATTNER, R.F. (1997) Management: Meeting and Exceeding Customer Expectations (6 ${ }^{\text {th }}$ ed.) South-Western College Publishing, Cincinnati, Ohio.

7 RUE, L.W. \& BYARS, L.L. (1989) Management: Theory and Application ( $5^{\text {th }}$ ed.) Richard D. Irwin, Homewood, Illinois.

8 SHRIVASTAVA, P. (1994) Strategic Management: Concepts and Practices, South-Western Publishing Co, Cincinnati, Ohio.

9 THOMPSON, J.L. (1997) Strategic Management: Awareness and Change $\left(3^{\text {rd }}\right.$ ed.) International Thomson Business Press, London.

10 VAN DER LITH, M. (1998) Facsimile from Financial Services Board.

11 WHEELEN, T.L. \& HUNGER, J.D. (1995) Strategic Management and Business Policy $\left(5^{\text {th }}\right.$ ed.) Addison-Wesley Publishing Company, Reading, Massachusetts. 